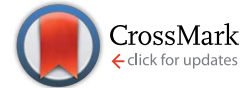

Cite this: J. Mater. Chem. A, 2015, 3, 6196

Received 5th December 2014 Accepted 10th February 2015

DOI: $10.1039 / c 4 t a 06692 \mathrm{~h}$

www.rsc.org/MaterialsA

\section{Single-step synthesis of nanostructured $\gamma$-alumina with solvent reusability to maximise yield and morphological purity}

\begin{abstract}
T. E. Bell, ${ }^{a}$ J. M. González-Carballo, ${ }^{b}$ R. P. Tooze ${ }^{b}$ and L. Torrente-Murciano*a
Insights of the chemical mechanism for the hydrothermal synthesis of nanostructured alumina are elucidated for the first time, demonstrating the effect of the $\mathrm{NaOH}$ : Al molar ratio not only on the resulting morphology of the material but also on the product yield. Highly uniform pure $\gamma-\mathrm{Al}_{2} \mathrm{O}_{3}$ nanorods are synthesised under acidic conditions $(\mathrm{pH}<4)$, while basic medium $\left(\mathrm{pH}>\right.$ 9) lead to $\gamma-\mathrm{Al}_{2} \mathrm{O}_{3}$ nanoplates. Maximisation of the morphological purity leads to a decrease in the overall aluminium yield which can be overcome by successful reusability of the synthesis medium in an effort to increase efficiency (yield and productivity) and minimise waste production towards feasible large-scale manufacturing of nanostructured materials.
\end{abstract}

\section{Introduction}

Alumina, $\mathrm{Al}_{2} \mathrm{O}_{3}$, is industrially used in a wide range of applications including adsorbents, abrasives, catalysts and catalysts supports. ${ }^{1-3}$ Amongst all alumina polymorphs, $\gamma-\mathrm{Al}_{2} \mathrm{O}_{3}$ has the highest specific surface area and is thus the favoured transition form for catalyst supports. ${ }^{4}$ Out of the numerable aluminium minerals such as the hydroxides and oxy hydroxides, boehmite $(\gamma$-AlOOH, aluminium oxy hydroxide), is often the most viable precursor to obtain $\gamma-\mathrm{Al}_{2} \mathrm{O}_{3}$, achieved by calcination at temperatures between 300 and $500{ }^{\circ} \mathrm{C} .{ }^{5,6} \gamma$-AlOOH presents an orthorhombic crystal structure which consists of octahedral $\mathrm{AlO}_{6}$ units coupled by hydrogen bonding in the $\{010\}$ direction forming a layered or lamellar structure. ${ }^{7}$ By contrast, the $\gamma-\mathrm{Al}_{2} \mathrm{O}_{3}$ crystal structure is analogous to that of spinel $\left(\mathrm{MgAl}_{2} \mathrm{O}_{4}\right)$ with additional tetragonal distortion due to the absence of divalent cations. ${ }^{8}$ Quantum mechanical calculations using density functional theory have successfully modelled the dehydration processes for the transformation of boehmite to $\gamma-\mathrm{Al}_{2} \mathrm{O}_{3}$ and suggest that $\gamma-\mathrm{Al}_{2} \mathrm{O}_{3}$ adopts the skeletal boehmite structure from which a proportion of $\mathrm{Al}$ atoms migrate to tetrahedral positions, explaining the conservation in morphology observed during the calcination of boehmite. ${ }^{9}$ Recently, anisotropic 1D nanostructured materials, have attracted significant attention in materials synthesis due to the possibility to tune the chemical and physical properties at the nanoscale. Indeed, the first report of the synthesis of $1 \mathrm{D}$ alumina (fibers) was only reported in 1996 at the Lawrence Berkeley Laboratory. Since then, the

\footnotetext{
${ }^{a}$ Department of Chemical Engineering and Centre for Sustainable Chemical Technologies, University of Bath, Bath, BA2 7AY, UK. E-mail: ltm20@bath.ac.uk; Tel: +441225385857

${ }^{b}$ Sasol Technology UK, Purdie Building, North Haugh, St Andrews, KY16 9ST, UK
}

reported methods for the synthesis of nanostructured $\gamma-\mathrm{Al}_{2} \mathrm{O}_{3}$ vary in terms of cost, complexity and the quality of the resulting material. Examples of methods include hydrothermal without $^{\text {10-12 }}$ and with $^{\text {13-19 }}$ structure directing agents (SDA), solgel, ${ }^{20-23}$ atomic layer deposition, ${ }^{3}$ wet etching of core-shell nanofibers, ${ }^{24}$ thermal evaporation ${ }^{25}$ and anodisation. ${ }^{26-28}$ Hydrothermal syntheses are an attractive route for obtaining 1D nanostructured $\gamma-\mathrm{Al}_{2} \mathrm{O}_{3}$ for their simplicity, reproducibility, low cost and ease of scale up. However, environmental issues associated with solvent waste are currently limiting the application of hydrothermal processes in manufacturing, an issue which is addressed in the synthetic procedure herein by its recycle in consecutive synthesis. Hydrothermal syntheses can be carried out with various SDAs such as surfactants, ${ }^{13-15}$ resins, ${ }^{16}$ ionic liquids,${ }^{17}$ glucose ${ }^{18}$ and carbon nanotubes ${ }^{19}$ to yield high quality 1D nanostructures. However, these synthetic procedures often require complicated work up and can cause defects in the crystal structure resulting in lower crystallinity of the final product. In the case of surfactants, they can affect the quality of the final material by the presence and adsorption of residual carbon from the aliphatic chain after their removal by calcination. Consequently, the hydrothermal synthesis of nanostructured $\gamma-\mathrm{Al}_{2} \mathrm{O}_{3}$ discussed herein excludes the use of any such SDAs, whilst maintaining well defined nanostructured morphologies. In this paper, insights of the chemical mechanism during the synthesis of nanostructured $\gamma-\mathrm{Al}_{2} \mathrm{O}_{3}$ is elucidated, as well as the effect of $\mathrm{NaOH}$ concentration on the final product morphology and yield in an effort to further understand the complexities of the hydrothermal synthesis of $\gamma-\mathrm{Al}_{2} \mathrm{O}_{3}$. In addition, the recyclability of the synthesis solution is demonstrated in order to address the solvent waste problem while remarkably increasing the aluminium atom efficiency and production towards the scale-up of this synthesis towards manufacturing. 


\section{Experimental}

Synthesis of $\gamma$-alumina nanorods

Boehmite nanorods are synthesised by hydrothermal treatment based on a modified method previously reported. ${ }^{10}$ In a typical synthesis, $4.8 \mathrm{~g}$ of aluminium nitrate nonahydrate $\left(\mathrm{Al}\left(\mathrm{NO}_{3}\right)_{3}\right.$ $\cdot 9 \mathrm{H}_{2} \mathrm{O}$ ) is dissolved in $20 \mathrm{~mL}$ of deionised water before adding $10 \mathrm{~mL} \mathrm{NaOH}$ solution of various concentrations. The combined $30 \mathrm{~mL}$ solution is transferred to a $45 \mathrm{~mL}$ Teflon lined stainless steel autoclave and treated hydrothermally for $20 \mathrm{~h}$ at $200{ }^{\circ} \mathrm{C}$ inside an air-circulating oven which allows uniform temperature to be achieved throughout the autoclave. After this time, the autoclave is allowed to cool to ambient temperature. The white powder obtained $(\gamma-\mathrm{AlOOH})$ is separated from the solution by centrifugation (4000 rpm, 20 minutes), washed several times with deionised water and dried overnight at $80^{\circ} \mathrm{C}$ under vacuum. Large particles of agglomerated, dry $\gamma$-AlOOH powder are broken in a mortar prior to further investigation. Finally, the $\gamma$-AlOOH powder is calcined at $500{ }^{\circ} \mathrm{C}$ for three hours $\left(3{ }^{\circ} \mathrm{C} \min ^{-1}\right.$ heating rate) to yield $\gamma-\mathrm{Al}_{2} \mathrm{O}_{3}$.

In specific cases, the synthesis solution separated from the $\gamma$-AlOOH solid product by centrifugation is recycled in consecutive synthesis prior to addition of the corresponding amount of reactants $\left(\mathrm{NaOH}\right.$ and $\left.\mathrm{Al}\left(\mathrm{NO}_{3}\right)_{3} \cdot 9 \mathrm{H}_{2} \mathrm{O}\right)$, following the procedure described above.

\section{Characterisation of $\gamma$-alumina nanostructured materials}

Transmission electron microscopy (TEM) was carried out using a JEOL JEM1200EXII instrument. Energy-dispersive X-ray spectroscopy (EDX) was used to confirm the chemical composition of the sample with a Thermo Fisher Scientific NORAN System 7. $\mathrm{N}_{2}$ adsorption measurements at $-196{ }^{\circ} \mathrm{C}$ were carried out using a Micromeritics ASAP 2020 apparatus. Specific surface area was calculated using the BET method and pore size distributions were calculated from the desorption data using the $\mathrm{BJH}$ model. Samples were degassed at $150{ }^{\circ} \mathrm{C}$ prior to analysis in order to calculate specific surface area.

Thermogravimetric analyses (TGA) were carried out using a TGA-DTA 92 Type 31/1190, Setsoft 2000 instrument from 25 to $600{ }^{\circ} \mathrm{C}$ at a heating rate of $10{ }^{\circ} \mathrm{C} \mathrm{min}^{-1}$ using nitrogen as a carrier gas. The phase identification of the samples was done by powder X-ray diffraction (XRD) analysis using a Bruker D8 Advance diffractometer and a position sensitive VANTEC-1 detector with $\mathrm{Cu} \mathrm{K} \alpha$ radiation, operated at $40 \mathrm{kV}$ and $40 \mathrm{~mA}$.

\section{Results and discussion}

The study of the effect of the initial concentration of $\mathrm{NaOH}$ base during the hydrothermal synthesis of nanostructured boehmite $(\gamma$ $\mathrm{AlOOH})$ in the absence of surfactant provides an insight into the chemical mechanism taking place during the synthesis. A systematic study of the synthesis of nanostructured boehmite by hydrothermal treatment at $200{ }^{\circ} \mathrm{C}$ over $20 \mathrm{~h}$ with different initial $\mathrm{NaOH}$ concentrations was carried out. Table 1 shows the different hydrothermal conditions including $\mathrm{pH}$ as well as the boehmite morphology obtained.

An initial $\mathrm{NaOH}$ concentration of $1 \mathrm{M}$, results in the formation of well-defined regular $1 \mathrm{D} \gamma$-AlOOH structures with average lengths of $260 \mathrm{~nm}$ and diameters of $27 \mathrm{~nm}$. High morphological purity is obtained under these conditions, without the presence of other morphologies or amorphous materials as confirmed by TEM (Fig. 1). Increasing the initial $\mathrm{NaOH}$ base concentration to 3.8 $\mathrm{M}$ during the synthesis results in a non-uniform combination of nanorods and a high proportion of $2 \mathrm{D}$ nanoplates of heterogeneous sizes. At higher $\mathrm{NaOH}$ base concentration values (5.9 M), a limited number of 1D structures are formed, with the majority of the product forming an irregular array of $2 \mathrm{D}$ nanoplates.

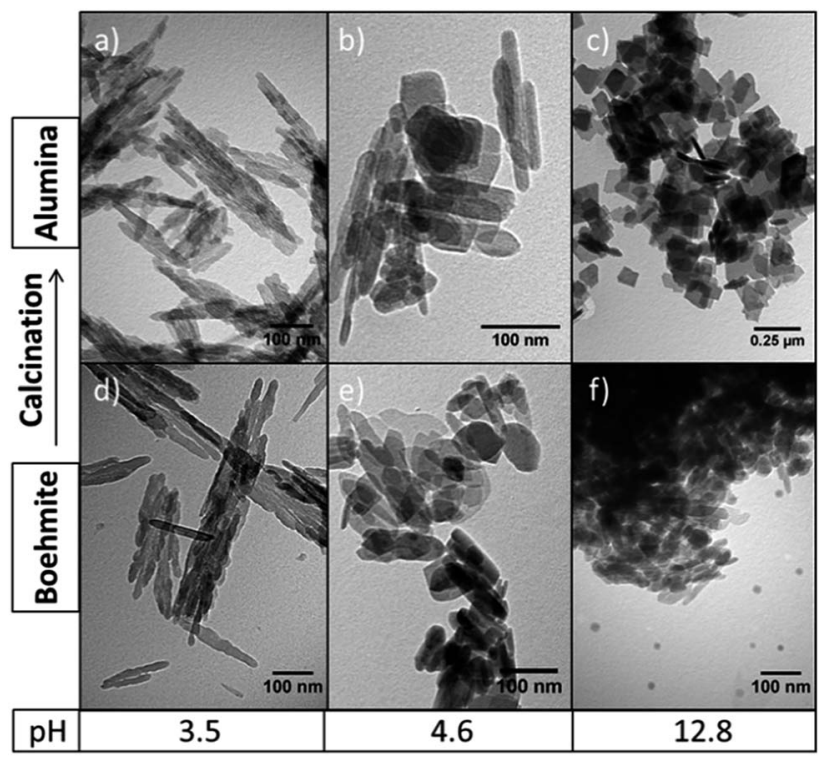

Fig. 1 Effect of $\mathrm{pH}$ of the solution on the morphology of $\gamma-\mathrm{Al}_{2} \mathrm{O}_{3}(\mathrm{a}-\mathrm{c})$ and $\gamma$-AlOOH $(d-f)$ from hydrothermal synthesis $\left(200{ }^{\circ} \mathrm{C}, 20 \mathrm{~h}\right)$.

Table 1 Hydrothermal conditions during the synthesis of $\gamma$-AlOOH at $200{ }^{\circ} \mathrm{C}$ for $20 \mathrm{~h}$ and their effect on the resulting morphology of $\gamma$-AlOOH and $\gamma-\mathrm{Al}_{2} \mathrm{O}_{3}$

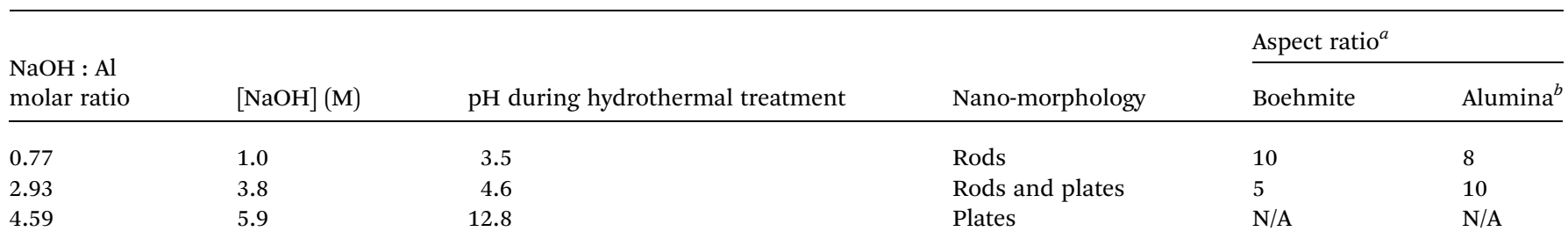

${ }^{a}$ Length: diameter ratio. ${ }^{b}$ After calcination at $500{ }^{\circ} \mathrm{C}$. 
Fig. 2 shows the differential of the thermogravimetric analyses for boehmite samples synthesised with 1 and $5.9 \mathrm{M} \mathrm{NaOH}$, corresponding to nanorods and nanoplates respectively. Both set of data are normalised per mass of material for easy comparison. The initial decrease in mass between 75 and $200{ }^{\circ} \mathrm{C}$ corresponds to the removal of adsorbed and interstitial water. Prior to the analyses, the materials were dried at $80{ }^{\circ} \mathrm{C}$ under vacuum, and consequently this removal of water suggests a hydroscopic boehmite nature. The loss of mass at high temperatures corresponds to the transformation of $\gamma-\mathrm{AlOOH}$ into $\gamma-\mathrm{Al}_{2} \mathrm{O}_{3}$, which takes place at a slightly lower temperature for the nanorods $\left(460{ }^{\circ} \mathrm{C}\right)$ compared with the nanoplates $\left(507^{\circ} \mathrm{C}\right)$. Based on these results a temperature of $500{ }^{\circ} \mathrm{C}$ is used for the calcination of boehmite, in agreement to the conditions used in the literature (between 300 and $500{ }^{\circ} \mathrm{C}$ )..$^{5,6}$ The enthalpy change corresponding to the endothermic, isomorphous transformation is $+8.98 \mathrm{~kJ} \mathrm{~mol}^{-1}$ and $+6.61 \mathrm{~kJ} \mathrm{~mol}^{-1}$ for the nanorods and nanoplates respectively. Fig. 1 shows representative TEM pictures of boehmite and alumina after calcinations, which confirm the literature expectations of a conservation of morphology after calcination. ${ }^{12}$ Interestingly, the lamellar structures stabilised at high base concentrations (5.9 M), under hydrothermal basic conditions, are stable at high temperatures.

The chemical transformations taking place during the boehmite synthesis is as follows; the dissolution of aluminium nitrate nonahydrate $\left(\mathrm{Al}\left(\mathrm{NO}_{3}\right)_{3} \cdot 9 \mathrm{H}_{2} \mathrm{O}\right)$ in an aqueous $\mathrm{NaOH}$ solution forms an initial white colloidal suspension of amorphous aluminium hydroxide $\left(\mathrm{Al}(\mathrm{OH})_{3}\right)$ according to reaction (1). $\mathrm{Al}(\mathrm{OH})_{3}$ is amphoteric and forms an equilibrium according to reaction (2) depending on a delicate balance of the concentration of hydroxide ions which determines the prevalence of $\mathrm{Al}(\mathrm{OH})_{3}$, the required precursor to $\gamma-\mathrm{AlOOH}$ and eventually $\gamma$ $\mathrm{Al}_{2} \mathrm{O}_{3}$. This equilibrium is also responsible of a variation of the $\mathrm{pH}$ of the solution before hydrothermal treatment. The $\mathrm{pH}$ values for each of the different concentrations of $\mathrm{NaOH}$ are shown in Table 1. At low concentrations of $\mathrm{NaOH}(<5.9 \mathrm{M})$, the hydrothermal treatment takes place under acidic conditions. At the other end of the $\mathrm{pH}$ scale, basic hydrothermal conditions exist with the use of higher initial $\mathrm{NaOH}$ concentrations $(>5.9 \mathrm{M})$.



Fig. 2 Differential thermogravimetric analyses of $\gamma$-AlOOH nanorods and nanoplates synthesised with $1 \mathrm{M}$ and $5.9 \mathrm{M} \mathrm{NaOH}$ respectively at $200{ }^{\circ} \mathrm{C}$ for $20 \mathrm{~h}$.

$$
\begin{gathered}
\mathrm{Al}\left(\mathrm{NO}_{3}\right)_{3} \cdot 9 \mathrm{H}_{2} \mathrm{O}(\mathrm{aq})+3 \mathrm{NaOH}(\mathrm{aq}) \rightarrow \mathrm{Al}(\mathrm{OH})_{3}(\mathrm{~s}) \\
+9 \mathrm{H}_{2} \mathrm{O}(\mathrm{l})+3 \mathrm{Na}^{+}(\mathrm{aq})+3 \mathrm{NO}_{3}{ }^{-}(\mathrm{aq}) \\
\mathrm{Al}(\mathrm{OH})_{3}(\mathrm{~s}) \stackrel{\mathrm{OH}^{-}(\mathrm{aq})}{\mathrm{H}^{+}(\mathrm{aq})} \mathrm{Al}(\mathrm{OH})_{4}{ }^{-}(\mathrm{aq}) \\
\mathrm{Al}(\mathrm{OH})_{3}(\mathrm{~s}) \rightarrow \gamma-\mathrm{AlOOH}(\mathrm{s})+\mathrm{H}_{2} \mathrm{O}(\mathrm{l}) \\
2 \gamma-\mathrm{AlOOH}(\mathrm{s}) \rightarrow \gamma-\mathrm{Al}_{2} \mathrm{O}_{3}(\mathrm{~s})+\mathrm{H}_{2} \mathrm{O}(\mathrm{l})
\end{gathered}
$$

Under hydrothermal conditions, a lamellar $\gamma$-AlOOH product is formed according to reaction (3). The final morphology of the resulting boehmite material strongly depends on the $\mathrm{pH}$ conditions during the synthesis. In acidic conditions, the presence of excess protons disrupts the hydrogen bonding between the layers allowing the lamellar boehmite structure to be separated into 2D layers which subsequently roll themselves to decrease their surface energy under a thermodynamic governed regime. Growth of the 1D structures, which determines the final aspect ratio of the nanostructures, follows the conventional dissolution-recrystallisation mechanism via Ostwalds ripening, as previously reported for similar boehmite materials ${ }^{\mathbf{1 0 , 1 1}}$ and other ceramic nanostructures, ${ }^{29}$ the rate of which is dictated by the specific synthesis conditions of each hydrothermal treatment. ${ }^{30}$

The results herein determine that an increase of $\mathrm{pH}$ within the acidic regime results in a lower nanorods purity with the presence of nanoplates likely formed during the Ostwald ripening process involved in the growth of the rods. ${ }^{\mathbf{1 0}}$ This observation does not agree with the results reported by Yang ${ }^{\mathbf{1 0}}$ where an increase in morphological purity and crystallinity of the boehmite nanorods is observed upon increasing $\mathrm{pH}$. The differences are likely to be due to variations in the experimental procedure (e.g. $\mathrm{NaOH}: \mathrm{Al}$ ratio).

An excess of $\mathrm{NaOH}$ concentration results in basic hydrothermal conditions which stabilise the lamellar structures by hydroxylation of the under coordinated surface $\mathrm{Al}$ atoms to inhibit scrolling of the sheets to form 1D materials. Complete stabilisation of these lamellar structures is observed with an initial 5.9 $\mathrm{M} \mathrm{NaOH}$ concentration, equivalent to a $\mathrm{pH}$ of 12.8 during the boehmite synthesis, as shown in Fig. 1. These results confirm the key role of protons on the breakage of the hydrogen bonding network between the boehmite lamellar structure which leads to metastable layers as precursors for the rods as previously hypothesised by some authors. ${ }^{\mathbf{1 0 , 1 1}}$

The equilibrium in reaction (2) also dictates the yield of boehmite product obtained as a function of the hydroxide ions initially present in the solution. Thus, the $\gamma-\mathrm{Al}_{2} \mathrm{O}_{3}$ yield (wt. \%) is defined as:

$$
\left(1-\frac{m_{\mathrm{Al}, \text { in }}-m_{\mathrm{Al}, \text { out }}}{m_{\mathrm{Al}, \text { in }}}\right) \times 100
$$

where $m_{\mathrm{Al} \text {,in }}$ and $m_{\mathrm{Al} \text {,out }}$ correspond to the mass of aluminium in the precursor and product respectively.

This chemical mechanism is evidenced by the variations of alumina yield as a function of the molar ratio of reactants $(\mathrm{NaOH}: \mathrm{Al})$ shown in reaction (1), irrespective of the resulting 
morphology. Specifically for this procedure, the stoichiometric ratio of $\mathrm{NaOH}: \mathrm{Al}\left(\mathrm{NO}_{3}\right)_{3} \cdot 9 \mathrm{H}_{2} \mathrm{O}$ in reaction (1) corresponds to an initial $\mathrm{NaOH}$ concentration of $3.8 \mathrm{M}$, leading to the maximum yield of the boehmite hydrothermal product, approaching 100\%. Fig. 3 shows the relationship between alumina yield (wt\%) and the $\mathrm{NaOH}: \mathrm{Al}\left(\mathrm{NO}_{3}\right)_{3} \cdot 9 \mathrm{H}_{2} \mathrm{O}$ molar ratio, where the error bars represent the amount of interstitial water in the product deduced by TGA analyses in Fig. 2. It is important to note that variations on the initial amount of aluminium precursor would consequently change this stoichiometric ratio. An increase of the $\mathrm{NaOH}: \mathrm{Al}\left(\mathrm{NO}_{3}\right)_{3} \cdot 9 \mathrm{H}_{2} \mathrm{O}$ molar ratio above its stoichiometric value $(<3.8 \mathrm{M}$ in this case) yields less boehmite product due to the lack of conversion of the aluminium precursor $\mathrm{Al}\left(\mathrm{NO}_{3}\right)_{3} \cdot 9 \mathrm{H}_{2} \mathrm{O}$ into $\mathrm{Al}(\mathrm{OH})_{3}$ prior to the hydrothermal treatment. Conversely, an initial excess of $\mathrm{NaOH}$ concentration above the stoichiometric $\mathrm{NaOH}: \mathrm{Al}\left(\mathrm{NO}_{3}\right)_{3} \cdot 9 \mathrm{H}_{2} \mathrm{O}$ molar ratio ( $>3.8 \mathrm{M}$ in this case) results in the dissolution of the $\mathrm{Al}(\mathrm{OH})_{3}$ colloids according to equilibrium in reaction (2), with the resulting aluminium yield decreasing as the $\mathrm{NaOH}$ concentration increases. No solid is formed at $\mathrm{NaOH}: \mathrm{Al}\left(\mathrm{NO}_{3}\right)_{3} \cdot 9 \mathrm{H}_{2} \mathrm{O}$ molar ratios above 5.2 due to the absence of $\mathrm{Al}(\mathrm{OH})_{3}$ during the hydrothermal conditions according to reaction (2).

As discussed before, the $\mathrm{NaOH}: \mathrm{Al}\left(\mathrm{NO}_{3}\right)_{3} \cdot 9 \mathrm{H}_{2} \mathrm{O}$ molar ratio also determines the resulting morphology of the products, making it possible to selectively obtain nanorods under acidic hydrothermal conditions $(\mathrm{pH} \sim 3.5)$ and nanoplates under basic conditions $(\mathrm{pH} \sim 12.8)$. In the cases where high morphological purity is achieved, the alumina yield does not exceed $50 \%$. Higher alumina yields result in a mixture of nanorods and nanoplate morphologies. In order to increase the overall alumina yield and in an effort to reduce solvent waste and increase atom efficiency, the recyclability of the synthesis solution was investigated.

For this, a boehmite synthesis with an initial $\mathrm{NaOH}$ concentration of $1 \mathrm{M}$ ( $\mathrm{pH} 3.5$ ) was carried out producing uniform nanorods with a final alumina yield of $43 \%$. After separation of the product, the synthesis medium was reused prior to addition of fresh precursors $\left(\mathrm{Al}\left(\mathrm{NO}_{3}\right)_{3} \cdot 9 \mathrm{H}_{2} \mathrm{O}\right.$ and $\mathrm{NaOH}$ ). Highly uniform boehmite nanorods were obtained,

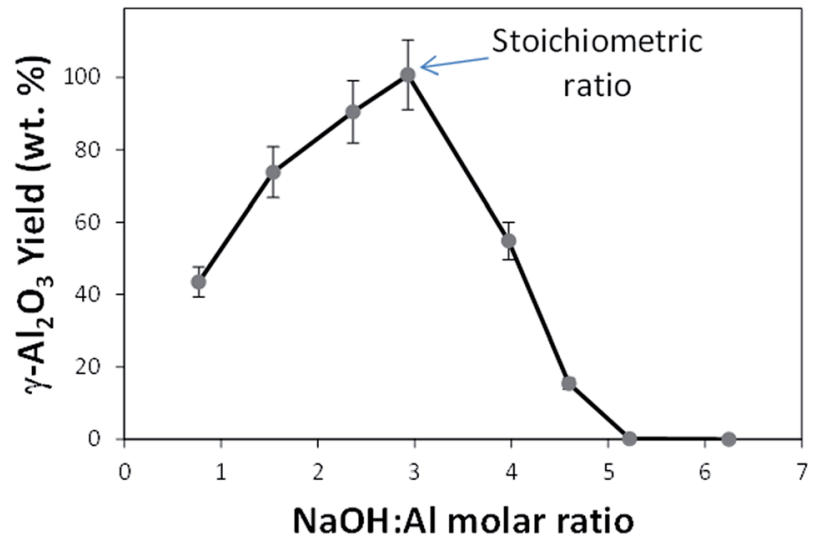

Fig. 3 Effect of the initial $\mathrm{NaOH}: \mathrm{Al}\left(\mathrm{NO}_{3}\right)_{3} \cdot 9 \mathrm{H}_{2} \mathrm{O}$ molar ratio during hydrothermal synthesis $\left(200{ }^{\circ} \mathrm{C}, 20 \mathrm{~h}\right.$ ) on the final $\gamma-\mathrm{Al}_{2} \mathrm{O}_{3}$ yield $(w t \%)$.

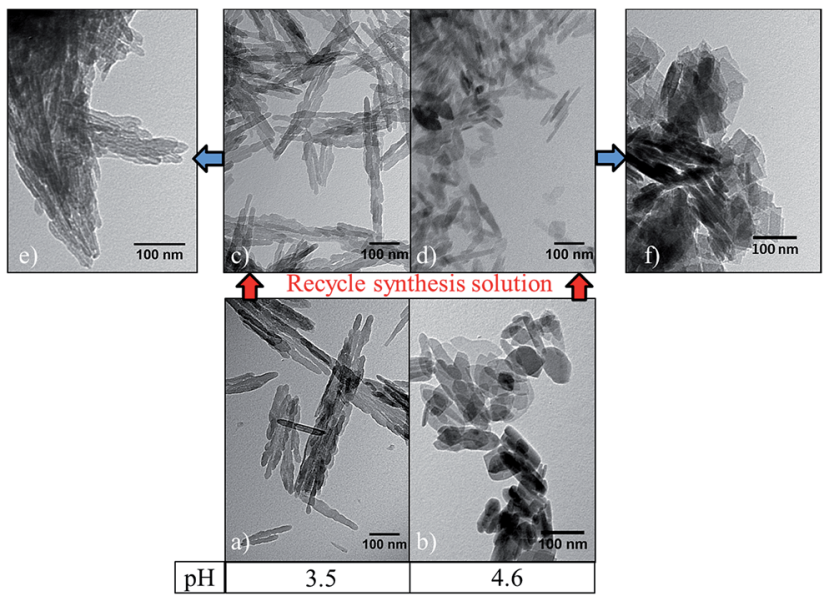

Fig. 4 Initial nanostructured $\gamma$-AlOOH hydrothermally synthesised $\left(200{ }^{\circ} \mathrm{C}, 20 \mathrm{~h}\right.$ ) at (a) pH 3.5 and (b) 4.6 and morphology of $\gamma$-AlOOH synthesised by recycle procedure from initial $\mathrm{pH}$ (c) 3.5 and (d) 4.6. (e) and (f) show the morphology of resulting $\gamma-\mathrm{Al}_{2} \mathrm{O}_{3}$ samples after calcination of (c) and (d) respectively.

increasing the alumina yield to $90 \%$ at least in four consecutive recycles. The morphology of the resulting $\gamma$-AlOOH and $\gamma-\mathrm{Al}_{2} \mathrm{O}_{3}$ materials from the consecutive assay are shown in Fig. 4. The reusability of the reaction medium is applicable to all the hydrothermal syntheses with different initial $\mathrm{NaOH}$ concentration studied herein as illustrated by a similar example at an initial $\mathrm{pH}$ of $4.6(3.9 \mathrm{M} \mathrm{NaOH})$, where a mixture of nanorods and nanoplates are produced (Fig. 4).

The X-ray diffraction patterns shown in Fig. 5 confirm the synthesis of orthorhombic boehmite materials during the hydrothermal treatment with major diffraction peaks at $2 \theta$ values of $15,28,38,48,55$ and $60^{\circ}$ (JCPDS 21-1307). However, as the hydrothermal $\mathrm{pH}$ conditions increase, additional diffraction peaks appear at $2 \theta$ values of $23,35,43,52,56$ and $62^{\circ}$, which cannot be attributed to the boehmite crystal structure. These peaks are believed to be related to the presence of residual $\mathrm{Na}$ from the high concentration of $\mathrm{NaOH}$ used in these conditions. This is further evidenced by EDS chemical analysis of the boehmite materials in which the nanorods synthesised under acidic hydrothermal conditions show the presence of only $\mathrm{Al}$ and $\mathrm{O}$ elements indicative of pure $\gamma$-AlOOH, whereas basic synthetic conditions yielded $\gamma$-AlOOH containing $\mathrm{Na}$. Especially significant is the diffraction peak at $2 \theta$ value of $29^{\circ}$ present in both, the boehmite and alumina nanoplates (Fig. 5b and d). A peak at the same diffraction angle was previously observed for another metal oxide, PbO, with increasing peak intensity as the concentration of $\mathrm{NaOH}$ increased. ${ }^{31}$ Indeed, the presence of $\mathrm{Na}$ in the product material is even more evident after reusing of the solvent due to the accumulation of $\mathrm{Na}$ cations (and nitrates anions). However, it is important to highlight that this accumulation does not have an apparent effect on the morphology of the resulting material. Further reusability cycles are however needed for a better understanding of the potential effect of $\mathrm{Na}$ and nitrate concentration on the reaction steps described above. 

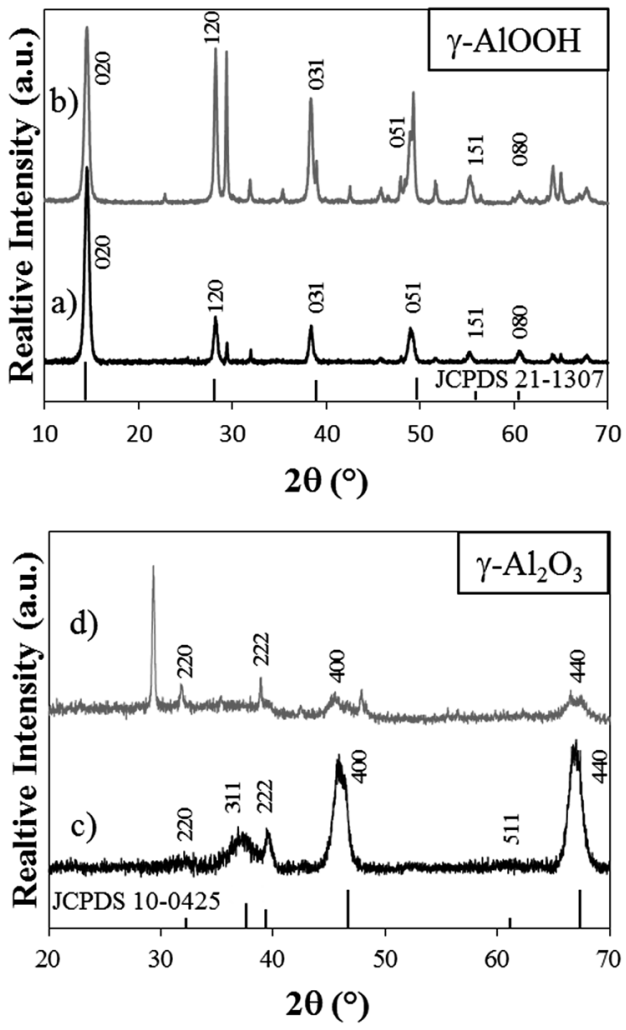

Fig. 5 Assigned X-ray diffraction pattern for $\gamma$-AlOOH (a) nanorods and (b) nanoplates synthesised under acidic and basic conditions respectively $\left(200{ }^{\circ} \mathrm{C}, 20 \mathrm{~h}\right)$ and $\gamma-\mathrm{Al}_{2} \mathrm{O}_{3}$ (c) nanorods and (d) nanoplates. (Acidic $=\mathrm{pH} 3.5$, basic $=\mathrm{pH}$ 12.8).

The $\mathrm{N}_{2}$ adsorption-desorption isotherms of boehmite and alumina nanorods synthesised under hydrothermal acidic conditions are shown in Fig. 6. The isotherm shows the presence of some microporosity and mesoporosity. The corresponding pore size distribution shows a bimodal distribution with pores $<2 \mathrm{~nm}$ corresponding to the porosity within the $1 \mathrm{D}$ material as well as a broad peak (10-40 nm) corresponding to the voids between the $1 \mathrm{D}$ rods. The subsequent BET surface area for boehmite and alumina synthesised at $\mathrm{pH} 3.5,4.6$ and 12.8 is summarised in Fig. 7. It is interesting to note the increase in BET surface area as a result of the transformation of boehmite into alumina by calcination, the effect of which is most prevalent for boehmite synthesised at $\mathrm{pH}$ 3.5. The relationship between an increased synthesis $\mathrm{pH}$ and the corresponding lower BET surface area has been previously reported in the literature. ${ }^{10}$

The surface area of the boehmite and the corresponding alumina synthesised with a recycled synthesis medium decreases from 46 to $30 \mathrm{~m}^{2} \mathrm{~g}^{-1}$ in the case of $\gamma$-AlOOH. The change in the physical properties are due to the alterations of the $\mathrm{NaOH}: \mathrm{Al}\left(\mathrm{NO}_{3}\right)_{3} \cdot 9 \mathrm{H}_{2} \mathrm{O}$ molar ratio and $\mathrm{pH}$ during consecutive hydrothermal treatment. In any case, the remarkable enhancement of the aluminium yield and production as well as the avoidance of waste solvent production set the foundations for further investigations to determine a feasible manufacturing route for continuous synthesis of high purity nanostructured $\gamma-\mathrm{Al}_{2} \mathrm{O}_{3}$.
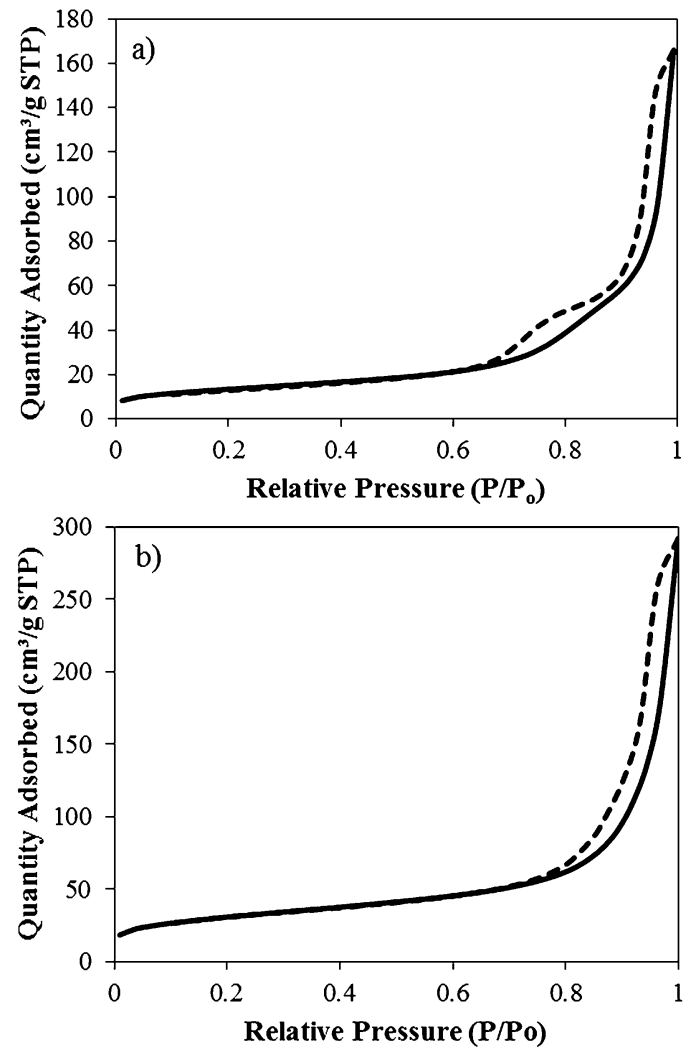

Fig. 6 Nitrogen adsorption-desorption isotherms at $-196^{\circ} \mathrm{C}$ of (a) $\gamma$ $\mathrm{AlOOH}$ synthesised at $200{ }^{\circ} \mathrm{C}$ for $20 \mathrm{~h}$ with $1 \mathrm{M} \mathrm{NaOH}$ and (b) corresponding $\gamma-\mathrm{Al}_{2} \mathrm{O}_{3}$ after calcination. (Adsorption = solid line, desorption $=$ dashed line)

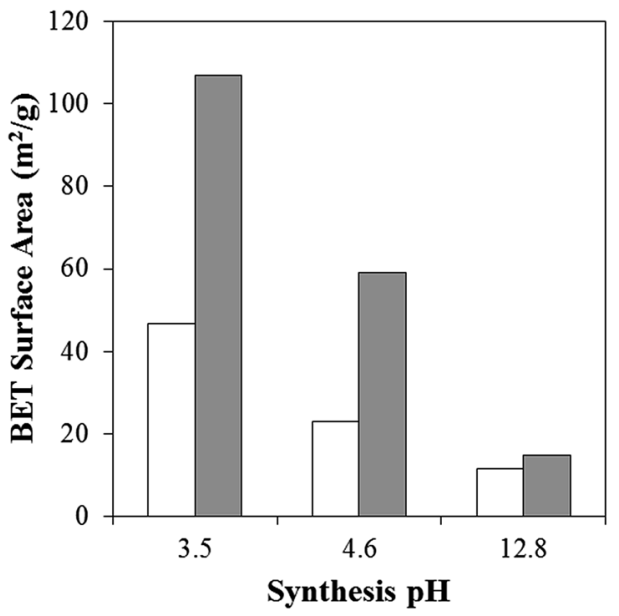

Fig. 7 BET specific surface area for boehmite (white) and alumina (grey) hydrothermally synthesised at $\mathrm{pH} 3.5,4.6$ and 12.8 for $20 \mathrm{~h}$ at $200^{\circ} \mathrm{C}$

\section{Conclusions}

The results presented herein and the understanding of the reaction steps during hydrothermal synthesis of nanostructured alumina establish that the resulting $\gamma-\mathrm{Al}_{2} \mathrm{O}_{3}$ morphology and yield is dependent not only upon the solution 
$\mathrm{pH}$ but also the $\mathrm{NaOH}: \mathrm{Al}\left(\mathrm{NO}_{3}\right)_{3} \cdot 9 \mathrm{H}_{2} \mathrm{O}$ molar ratio. Highly crystalline $\gamma-\mathrm{Al}_{2} \mathrm{O}_{3}$ nanorods with high morphological purity are synthesised by hydrothermal treatment at initial $\mathrm{pH} 3.5$ and $1: 1$ reactant ratio for $20 \mathrm{~h}$ at $200{ }^{\circ} \mathrm{C}$. Conversely, $\gamma-\mathrm{Al}_{2} \mathrm{O}_{3}$ nanoplates with heterogeneous sizes are formed as a result of the same hydrothermal procedure with initial pH 5.9 and $\mathrm{NaOH}$ : Al molar ratio of 4.6. The synthetic procedure has been demonstrated to be viable for manufacturing scale up by recycling of the reaction solution, maximizing the use of precursors (yield) and productivity and reducing solvent waste.

\section{Acknowledgements}

The authors would like to acknowledge the UK Engineering and Physical Science Research Council (grant number EP/L020432/ 1) for funding, the DTC in the Centre for Sustainable Chemical Technologies (grant number EP/G03768X/1) and SASOL UK for TEB's studentship.

\section{Notes and references}

1 W. Cai, Y. Hu, J. Chen, G. Zhang and T. Xia, CrystEngComm, 2012, 14, 972-977.

2 Y. Z. M. Ma, G. Cheng and Y. Huang, J. Mater. Sci. Technol., 2008, 24, 1812-1815.

3 J. S. Lee, B. Min, K. Cho, S. Kim, J. Park, Y. T. Lee, N. S. Kim, M. S. Lee, S. O. Park and J. T. Moon, J. Cryst. Growth, 2003, 254, 443-448.

4 O. Atkins, Rourke, Weller and Armstrong, Shriver \& Atkins Inorganic Chemistry, Oxford University Press, Oxford, 5th edn, 2010.

5 M. F. Peintinger, M. J. Kratz and T. Bredow, J. Mater. Chem. A, 2014, 2, 13143-13158.

6 B. Kasprzyk-Hordern, Adv. Colloid Interface Sci., 2004, 110, 19-48.

7 H. S. H. a. S. Xiang Ying Chen, Nanotechnology, 2007, 18, 285608.

8 M. Trueba and S. P. Trasatti, Eur. J. Inorg. Chem., 2005, 2005, 3393-3403.

9 X. Krokidis, P. Raybaud, A.-E. Gobichon, B. Rebours, P. Euzen and H. Toulhoat, J. Phys. Chem. B, 2001, 105, 5121-5130.

10 Q. Yang, Inorg. Mater., 2010, 46, 953-958.

11 Y. X. H. Hou, Q. Yang, Q. Guo and C. Tan, Nanotechnology, 2005, 16, 741-745.
12 M.-G. Ma, Y.-J. Zhu and Z.-L. Xu, Mater. Lett., 2007, 61, 18121815.

13 H. C. Lee, H. J. Kim, S. H. Chung, K. H. Lee, H. C. Lee and J. S. Lee, J. Am. Chem. Soc., 2003, 125, 2882-2883.

14 Z. Zhang and T. J. Pinnavaia, Langmuir, 2010, 26, 1006310067.

15 L. Qu, C. He, Y. Yang, Y. He and Z. Liu, Mater. Lett., 2005, 59, 4034-4037.

16 H. A. Dabbagh and M. Shahraki, Microporous Mesoporous Mater., 2013, 175, 8-15.

17 T. Kim, J. Lian, J. Ma, X. Duan and W. Zheng, Cryst. Growth Des., 2010, 10, 2928-2933.

18 B. Xu, T. Xiao, Z. Yan, X. Sun, J. Sloan, S. L. González-Cortés, F. Alshahrani and M. L. H. Green, Microporous Mesoporous Mater., 2006, 91, 293-295.

19 Y. Zhang, J. Liu, R. He, Q. Zhang, X. Zhang and J. Zhu, Chem. Phys. Lett., 2002, 360, 579-584.

20 M. Sasani Ghamsari, M. A. Abdul-Hamid, S. Radiman, A. H. Sasani Ghamsari and S. Rahmani, Mater. Lett., 2013, 106, 439-442.

21 S. C. Kuiry, E. Megen, S. D. Patil, S. A. Deshpande and S. Seal, J. Phys. Chem. B, 2005, 109, 3868-3872.

22 F. Rashidi, A. N. Kharat, A. M. Rashidi, E. Lima, V. Lara and J. S. Valente, Eur. J. Inorg. Chem., 2010, 2010, 1544-1551.

23 J. N. D. de Leon, V. Petranovskii, J. A. de los Reyes, G. AlonsoNunez, T. A. Zepeda, S. Fuentes and J. L. Garcia-Fierro, Appl. Catal., A, 2014, 472, 1-10.

24 J. Hwang, B. Min, J. S. Lee, K. Keem, K. Cho, M. Y. Sung, M. S. Lee and S. Kim, Adv. Mater., 2004, 16, 422-425.

25 X. X. Q. Zhao, H. Zhang, Y. Chen, J. Xu and D. Yu, Appl. Phys. A: Mater. Sci. Process., 2004, 79, 1721-1724.

26 L. Pu, X. Bao, J. Zou and D. Feng, Angew. Chem., Int. Ed., 2001, 40, 1490-1493.

27 J. Zou, L. Pu, X. Bao and D. Feng, Appl. Phys. Lett., 2002, 80, 1079-1081.

28 L. Yi, L. Zhiyuan, H. Xing, L. Yisen and C. Yi, Chem. Commun., 2011, 47, 2173-2175.

29 L. Torrente-Murciano, A. A. Lapkin and D. Chadwick, J. Mater. Chem., 2010, 20, 6484-6489.

30 L. Torrente-Murciano, A. Gilbank, B. Puertolas, T. Garcia, B. Solsona and D. Chadwick, Appl. Catal., B, 2013, 132-133, 116-122.

31 J. Pan, Y. Sun, W. Li, J. Knight and A. Manthiram, Nat. Commun., 2013, 4, 2178-2183. 